\title{
REVIEW ARTICLE OPEN Advancing antimicrobial strategies for managing oral biofilm infections
}

\author{
Yang Jiao ${ }^{1}$, Franklin R. Tay ${ }^{2}$, Li-na $\mathrm{Niu}^{3}$ and Ji-hua Chen ${ }^{3}$
}

\begin{abstract}
Effective control of oral biofilm infectious diseases represents a major global challenge. Microorganisms in biofilms exhibit increased drug tolerance compared with planktonic cells. The present review covers innovative antimicrobial strategies for controlling oral biofilm-related infections published predominantly over the past 5 years. Antimicrobial dental materials based on antimicrobial agent release, contact-killing and multi-functional strategies have been designed and synthesized for the prevention of initial bacterial attachment and subsequent biofilm formation on the tooth and material surface. Among the therapeutic approaches for managing biofilms in clinical practice, antimicrobial photodynamic therapy has emerged as an alternative to antimicrobial regimes and mechanical removal of biofilms, and cold atmospheric plasma shows significant advantages over conventional antimicrobial approaches. Nevertheless, more preclinical studies and appropriately designed and well-structured multi-center clinical trials are critically needed to obtain reliable comparative data. The acquired information will be helpful in identifying the most effective antibacterial solutions and the most optimal circumstances to utilize these strategies.
\end{abstract}

International Journal of Oral Science (2019)11:28; https://doi.org/10.1038/s41368-019-0062-1

\section{INTRODUCTION}

Biofilm-related infections pose a major problem in the society from both an economical and health perspective. ${ }^{1,2}$ Biofilms are defined as "aggregates of micro-organisms in which the associated cells are frequently embedded in a self-produced matrix of extracellular polymeric substances (EPS) that are adherent to each other and/or a surface. ${ }^{1 "}$ The EPS matrix not only provides microorganisms with a multilayered scaffold in which most cells experience cell-to-cell contact, either in flocs or in surfaceattached biofilms, but also creates a microenvironment that is different from other sites in terms of key environmental inputs known to affect microbial behaviors, including $\mathrm{pH}$, redox, and nutrient availability. ${ }^{3}$ Compared with planktonic microorganisms, the microorganisms in mature biofilm show increased tolerance to antimicrobial agents. ${ }^{4}$ It is estimated that biofilms contain multiple microbial species that weigh as high as $10^{8}$ $-10^{11}$ cells $^{-1}$ wet weight. ${ }^{5}$ The classical biofilm lifecycle may be described as a multi-stage process involving microbial attachment, biofilm maturation, and biofilm dispersal. ${ }^{6}$ Strategies that can disrupt any stage of biofilm formation are considered potentially valuable in controlling biofilm-related infections.

The warm, moist, and nutritious oral environment provides an ideal hatchery for microbial growth and proliferation. The complex dynamic interactions among microorganisms, host and diet result in microbial colonization and the subsequent formation of pathogenic biofilms. Biofilms formation on either tooth or dental material surfaces, known as oral biofilms, have been clearly recognized as a virulence factor in many oral infectious diseases, including dental caries, periodontitis and endodontic infections. ${ }^{7,8}$ Restorations, non-surgical or surgical periodontal therapies, root canal therapy, and dental implants are well-accepted therapeutic regimens, but secondary biofilm infections cannot be completely eliminated. Because of the increased drug tolerance, the complexity of the oral cavity and the rapid clearance of saliva, topical application of antimicrobial agents cannot be maintained at an effective concentration at the site of interest for a long enough period. The consequences of these infections depend on the location of biofilms and features of dental materials. ${ }^{9}$ Acid production by biofilms at the tooth-restoration margin causes secondary caries, which is a main reason for restoration failures. Pulp infections have also been clinically observed after dental restorations. Persisting biofilms inside the root canal system after root canal therapy may result in re-infections and persistent apical periodontitis. Biofilms on periodontal tissues and dental implants may cause periodontitis and peri-implantitis. The long-term clinical success of oral rehabilitation procedures depends on the capacity of dental materials to incorporate specific antimicrobial strategies for controlling and/or eradicating these infections. The present review encompasses a critical appraisal of recently published, innovative antimicrobial strategies for controlling oral biofilm-related infections.

\section{ANTIMICROBIAL DENTAL MATERIALS}

Antimicrobial materials to prevent bacterial adhesion and biofilm formation are of increasing importance because of the significant burden derived from surface-associated infections. Extensive efforts have been made to render dental materials with antimicrobial property. There are three major strategies: antimicrobial agent release, contact-killing, and multi-function ${ }^{10}$

\footnotetext{
${ }^{1}$ Department of Stomatology, the 7th Medical Center of PLA General Hospital, Beijing, PR China; ${ }^{2}$ Department of Endodontics, the Dental College of Georgia, Augusta University,

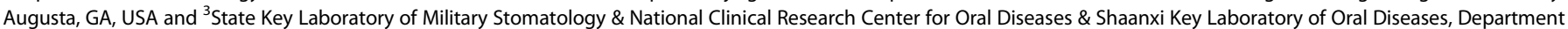
of Prosthodontics, School of Stomatology, the Fourth Military Medical University, Xi'an, PR China

Correspondence: Li-na Niu (niulina831013@126.com) or Ji-hua Chen (jhchen@fmmu.edu.cn)
}

Received: 22 February 2019 Revised: 2 August 2019 Accepted: 4 August 2019

Published online: 01 October 2019 
Table 1. Summary of strategies for antimicrobial dental materials

\begin{tabular}{lll}
\hline Name & Advantages & Drawbacks \\
\hline $\begin{array}{l}\text { Antimicrobial agent release } \\
\text { (locally) }\end{array}$ & $\begin{array}{l}\text { Strong and broad-spectrum antimicrobial activity, high local doses at } \\
\text { site of interest, less systemic toxicity, and minimize the risk of } \\
\text { antimicrobial resistance }\end{array}$ \\
$\begin{array}{ll}\text { Contact-killing } \\
\text { Multi-functional strategy }\end{array}$ & $\begin{array}{l}\text { Multiple functions (e.g., antibacterial, antifungal, antiviral, } \\
\text { remineralizing, protein-repellent properties) }\end{array}$ & Selection of more combinations for synergistic \\
& & antimicrobial and beneficial properties
\end{tabular}

(Table 1). Representative antimicrobial agents used for these strategies and their modes of action are listed in Table 2.

\section{Antimicrobial agent release}

The idea of producing release-based antimicrobial materials dates back to 1950s, when Colton et al. incorporated antibiotic drugs into dental cements and resins. ${ }^{11}$ This strategy has since attracted considerable attention. These materials exert their antimicrobial activity by releasing preloaded antimicrobial agents over time into the environment to kill bacteria. ${ }^{12}$ Compared with systemic drug delivery, local delivery of antibiotics from the material surface offers advantages including high local doses of antimicrobial agents at a specific site without exceeding systemic toxicity and thus minimizing the development of resistance. ${ }^{12}$ The first generation of release-based agents are mainly antibiotics or silver compounds. ${ }^{13}$ Silver compounds are effective against biofilms even at a very low concentration to prevent bacterial growth. Their strong and broad-spectrum antimicrobial characteristics involve the induction of oxidative stresses, deactivation of bacterial enzymes by binding to thiol groups, and an increase in the permeability of bacteria cell membranes. ${ }^{14}$ Nevertheless, these release-based systems suffer from their inherently limited reservoirs of antimicrobial agents, and lack of long-term properties. Dental materials evolve with the introduction of nanotechnology either through the development of new materials or improvements in the properties of existing materials. ${ }^{15,16}$ The unique properties of nanoparticles (NPs), such as their small size, high surface area, and capability of releasing high levels of ions at low incorporated amounts, distinguish them from the same materials in micro-size or bulk size. ${ }^{17}$ Many nanomaterials, such as $\mathrm{Ag}, \mathrm{Cu}, \mathrm{TiO}_{2}, \mathrm{ZnO}$, chitosan, and quaternary ammonium polyethylenimine (QPEI) NPs have been effective in controlling biofilms and incorporated into polymer matrices as filler particles. $^{14}$

Apart from conventional biocidal antimicrobial agents, researchers devised new methods of combining dental materials with bacterial signaling pathway (e.g. quorum-sensing) inhibitors. The latter include NO donors, ${ }^{18}$ natural products such as tea, ${ }^{19}$ and antioxidants such as $\mathrm{N}$-acetylcysteine, ${ }^{20}$ all of which have been shown to limit bacteria adhesion and biofilm formation. Bacterial attachment and subsequent formation of biofilm on surfaces result in changes in the local microenvironment, such as reduction in $\mathrm{pH}$ levels and release of bacterial products (e.g. specific enzymes) or virulence factors. ${ }^{3}$ The recently developed "smart" drug-delivery systems encompass "turn on" biocidal activity in response to a bacteria-containing microenvironment. This is achieved either by exposure of the surface-bound biocidal groups or release of preloaded antibiotics. ${ }^{21}$ For example, $\mathrm{pH}$-activated polymeric NPs loaded with farnesol are capable of releasing the active drug at cariogenic acidic $\mathrm{pH}(4.5-5.5)$. These novel NPs effectively disrupted $S$. mutans biofilm and attenuated biofilm virulence in an in vivo dental caries model. ${ }^{22}$ Nevertheless, releasebased antimicrobial dental materials still require extensive investigations before they may be recommended for clinical applications. Innovative strategies for controlling release kinetics within the therapeutic window, balance between the ability to kill bacteria and cytotoxicity to eukaryotes, and long-term effectiveness in case of secondary infections are desirable and ultimately govern the success of these materials.

\section{Contact-killing}

To circumvent the reservoir exhaustion issue of release-based antimicrobial materials, contact-killing strategy utilizes antimicrobial agents that are covalently anchored to the polymer backbone (Fig. 1). ${ }^{22}$ In this strategy, the antimicrobial agents used range from synthetic chemicals, such as quaternary ammonium compounds (QACs) and polycations to natural biomolecules such as antimicrobial peptides (AMPs). ${ }^{23}$

The use of QACs as antiseptics and disinfectants has a history of nearly one century. To date, the worldwide consumption of QACs is reported to exceed 0.7 million tons. ${ }^{24}$ Structurally, QACs are composed of nitrogen $\left(\mathrm{N}^{+}\right)$-containing compounds in which the $\mathrm{N}$ atom is attached to four different groups by covalent bonds. The representative formula is $N^{+} R_{1} R_{2} R_{3} R_{4} X^{-}$, where $R$ can be a hydrogen atom, a plain alkyl group or an alkyl group substituted with other functionalities, and $X$ represents an anion, which is most often a halide anion, although in some preparations, a hydroxyl anion may be involved. QACs are cationic surfactants and antimicrobials with broad-spectrum and strong contact-killing activity toward both Gram-positive and Gram-negative bacteria, fungi, malaria, amoebas, and viruses. ${ }^{25}$ The antimicrobial effect of QACs has been perceived as a function of the equilibrium among multiple factors including molecular weight, length of the $\mathrm{N}$-alkyl chain and counter anions. ${ }^{23}$ Although not fully elucidated, the antimicrobial mechanism of QACs is generally believed to be attributed to disruption of the bacterial cell membrane structures. $^{26}$ There are three methods to synthesize polymeric materials with pendant QACs. The first involves quaternization of polymers containing either tertiary ammonium groups or alkyl halides. The shortcomings of such an approach are the unpredictable impact of neighboring groups and limited degree of quaternization due to steric hindrance. Preparation of polymerizable quaternary ammonium monomers (QAMs), which are subsequently polymerized or copolymerized into a polymer network, has been developed for fabrication of QA-based dental materials. Another method is to incorporate QAC as a filler particle, such as the wellknown QPEI NPs. ${ }^{27,28}$ The first synthetic QAM to be incorporated in antibacterial dental materials is 12-methacryloyloxy dodecyl pyridinium bromide (MDPB), which was commercialized as an antibacterial adhesive system (Clearfil Protect Bond ${ }^{\mathrm{TM}}$, Kuraray Noritake Dental Inc., Tokyo, Japan). ${ }^{29,30}$ Unpolymerized MDPB exhibits strong antibacterial effects on various oral bacteria and biofilms. The minimum inhibitory concentration (MIC) and minimum bactericidal concentration (MBC) of MDPB against the seven cariogenic oral streptococci range from $31.3 \mu \mathrm{g} \cdot \mathrm{mL}^{-1}$ to $62.5 \mu \mathrm{g} \cdot \mathrm{mL}^{-1}{ }^{31}$ Compared with MDPB $\left(15.6 / 62.5 \mu \mathrm{g} \cdot \mathrm{mL}^{-1}\right)$, unpolymerized methacryloxyl ethylcetyldimethylammonium chloride (DMAE-CB) exhibits lower MIC/MBC $\left(3.91 / 7.81 \mu \mathrm{g} \cdot \mathrm{mL}^{-1}\right)$ values against $S$. mutans. DMAE-CB also demonstrates potent killing effects at relatively lower concentrations than MDPB against both planktonic and adhering bacteria; this result is indicative that DMAE-CB has stronger antibacterial activity. ${ }^{32,33}$ After curing, 


\begin{tabular}{|c|c|c|c|}
\hline \multirow[t]{5}{*}{ Antibiotics } & $\begin{array}{l}\text { Aminoglycosides (e.g., gentamicin, } \\
\text { tobramycin) }\end{array}$ & $\begin{array}{l}\text { Bind to the bacterial } 305 \text { ribosomal subunit and inhibit protein } \\
\text { synthesis }\end{array}$ & \multirow[t]{5}{*}{12} \\
\hline & Glycopeptides (e.g., vancomycin) & $\begin{array}{l}\text { Bind to amino acids and disrupt cell wall peptidoglycan } \\
\text { synthesis }\end{array}$ & \\
\hline & Penicillins (e.g., ampicillin) & $\begin{array}{l}\text { Inhibit related enzymes and disrupt cell wall peptidoglycan } \\
\text { synthesis }\end{array}$ & \\
\hline & Rifamycins (e.g., rifampin) & Bind to RNA polymerase and inhibit transcription & \\
\hline & Tetracyclines (e.g., minocycline, tetracycline) & Inhibit protein synthesis & \\
\hline $\begin{array}{l}\text { Antimicrobial } \\
\text { enzymes (AMEs) }\end{array}$ & Lysozyme & $\begin{array}{l}\text { Catalyze glycosidic bond hydrolysis in bacterial cell wall } \\
\text { peptidoglycans }\end{array}$ & 10 \\
\hline $\begin{array}{l}\text { Antimicrobial } \\
\text { peptides (AMPs) }\end{array}$ & $\begin{array}{l}\text { Synthetic AMPs (e.g., } \beta-17 \text {, human neutrophil } \\
\text { peptides } 1 \text { and } 2 \text {, histatins } 5 \text { and } 8 \text { ) }\end{array}$ & & 48,156 \\
\hline \multirow[t]{4}{*}{ Cationic compounds } & Chitosan & $\begin{array}{l}\text { Interaction between positively charged chitosan molecules and } \\
\text { negatively charged bacterial cell membranes leads to } \\
\text { disruption of cell membrane }\end{array}$ & \multirow{4}{*}{157} \\
\hline & Chlorhexidine & Bind to negatively charged bacterial walls and disrupt cell walls & \\
\hline & Poly( $\varepsilon$-lysine) & $\begin{array}{l}\text { Electrostatic adsorption onto bacterial cell membranes and } \\
\text { stripping of the outer membrane, resulting in cell death }\end{array}$ & \\
\hline & Quaternary ammonium compounds (QACs) & $\begin{array}{l}\text { Disruption of bacterial enzymes and cell membranes by } \\
\text { positively charged polymers }\end{array}$ & \\
\hline Metal and metal oxides & Ag NPs & $\begin{array}{l}\text { Induce oxidative stresses, deactivate bacterial enzymes by } \\
\text { binding to thiol groups and affect the function and } \\
\text { permeability of the cell membranes }\end{array}$ & 14,158 \\
\hline $\begin{array}{l}\text { Other non-cationic } \\
\text { compounds }\end{array}$ & Triclosan & $\begin{array}{l}\text { Deactivate bacterial fatty acid biosynthesis through inhibition } \\
\text { of the enoylacyl carrier protein reductase enzyme }\end{array}$ & 161,162 \\
\hline \multirow[t]{3}{*}{ Natural products } & Tea (e.g., tea catechins) & $\begin{array}{l}\text { Irreversible damage to the microbial cytoplasmic membrane, } \\
\text { inhibit the activity of salivary amylase, leading to reduced } \\
\text { cariogenicity of starch-containing foods }\end{array}$ & 19 \\
\hline & Propolis (e.g., trans-trans farnesol) & The lipophilic moiety interaction with bacterial membrane & 163 \\
\hline & Cranberry (e.g., proanthocyanins, flavonol) & $\begin{array}{l}\text { Inhibition of biofilm formation to prevent bacterial } \\
\text { coaggregation, reduction of bacterial hydrophobicity, and } \\
\text { alternation of cell surface molecules }\end{array}$ & 164 \\
\hline Amino acids & Arginine & $\begin{array}{l}\text { Counter the acid stress imposed by acidogenic bacteria and } \\
\text { maintain a healthy oral biofilm }\end{array}$ & 3 \\
\hline Antioxidants & $\mathrm{N}$-acetylcysteine (NAC) & $\begin{array}{l}\text { Inhibit bacterial cysteine, react with bacterial cell proteins, } \\
\text { reduce bacterial extracellular polymeric substances, and } \\
\text { disturb intracellular redox equilibrium }\end{array}$ & 152 \\
\hline
\end{tabular}

QAM-based dental materials such as resin composites, dental adhesives, glass ionomer cements (GICs), and resin-modified GICs, pit-and-fissure sealants, pulp capping materials, root canal sealers and acrylic resins exhibit "contact inhibition" effects on bacteria that contact their surfaces. ${ }^{34}$ Other polymerizable QAMs have been synthesized and their antibacterial activities have been investigated in previously published reports, using various bacteria strains. $^{35,36}$ The first generation of QAMs are monomethacrylates with only one methacrylate group, which unavoidably limits their incorporation into resin polymer network structures (5wt $\%$ MDPB and $3 \mathrm{wt} \%$ DMAE-CB in adhesives). Incorporating high concentrations of mono-methacrylates beyond the polymerizable capability of resin polymer network may inevitably affect their structures and mechanical properties. By 
a

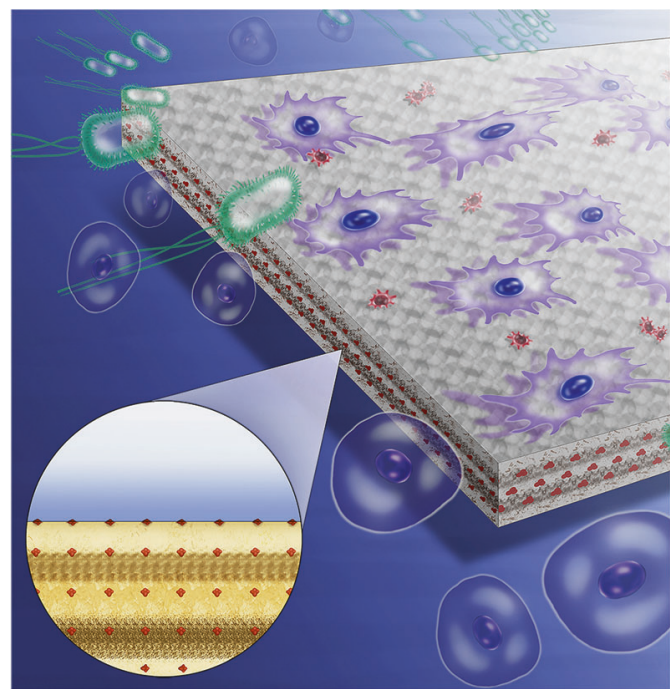

b

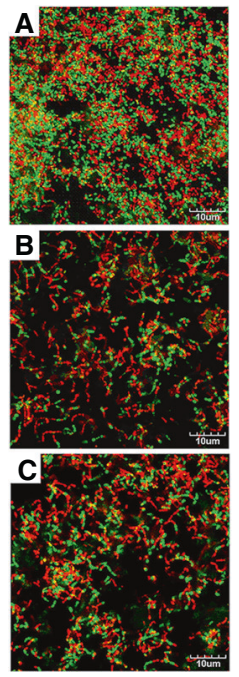

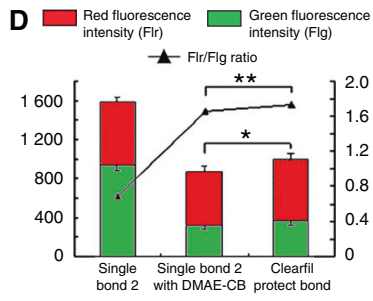

E
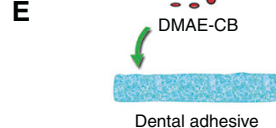

ental adhesive
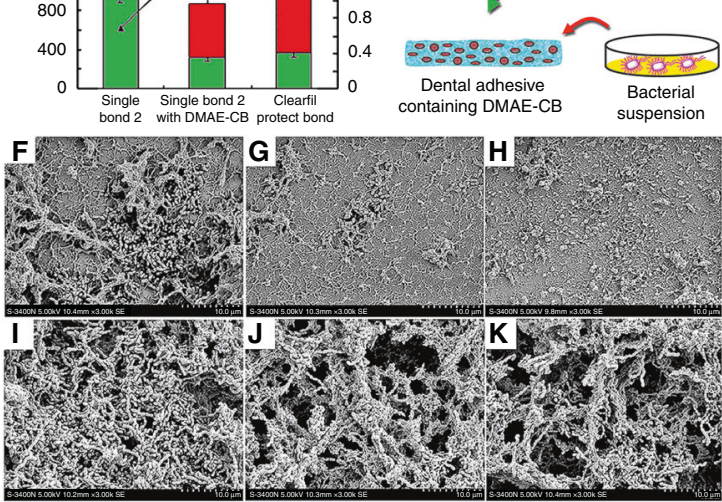

Fig. 1 The application of antimicrobial dental materials. a Schematic illustration of antimicrobial dental materials. Proper incorporation of antimicrobial agents endows dental materials with antimicrobial function (dead microorganisms in red) and good biocompatibility (wellstretched viable cells in purple). b Antibacterial activity of polymerized dental adhesives containing MDPB or DMAE-CB. Representative confocal laser scanning microscopy images of S. mutans adhered on the control adhesive A, adhesive containing MDPB B and adhesive containing DMAE-CB C after 24-h incubation. Bacteria with integral membranes were stained with green fluorescence and those with compromised membranes were stained with red fluorescence. D Fluorescence intensity values of the two channels for adhesives derived from the three groups. E Schematic representation of polymerized adhesive containing DMAE-CB. Representative scanning electron microscopy images of $S$. mutans biofilms on the control adhesive $\mathbf{F}$, adhesive containing MDPB $\mathbf{G}$, and adhesive containing DMAE-CB $\mathbf{H}$ after 4-h incubation. Representative scanning electron microscopy images of S. mutans biofilms on the control adhesive $\mathbf{I}$, adhesive containing MDPB J, and adhesive containing DMAE-CB K after 24-h incubation. ${ }^{22}$ Copyright 2017. Reproduced with permission from Elsevier Ltd

harnessing the groundbreaking advancements in organic chemistry and materials science, QAMs with dimethacrylate groups have been synthesized to enhance their polymerization within a resin network. For example, 2-methacryloxylethyl dodecyl methyl ammonium bromide (MAE-DB) and 2-methacryloxylethyl hexadecyl methyl ammonium bromide (MAE-HB) have been synthesized. These QAMs with dimethacrylate groups exhibit strong bactericidal activity, as evidence by their considerably lower MBC values against eight species of oral bacteria, ranging from $12.2 \mu \mathrm{g} \cdot \mathrm{mL}^{-1}$ to $24.4 \mu \mathrm{g} \cdot \mathrm{mL}^{-1}$ for MAE-DB, and $6.2 \mu \mathrm{g} \cdot \mathrm{mL}^{-1}$ to $48.8 \mu \mathrm{g} \cdot \mathrm{mL}^{-1}$ for MAE-HB. ${ }^{37,38}$ Likewise, dental materials containing bis(2-methacryloyloxy-ethyl) dimethyl-ammonium bromide, which has a low viscosity and can be easily mixed with common dimethacrylates, exhibited strong anti-bacterial/anti-biofilm ability and the antibacterial effects may be retained for 6 months. The improved antimicrobial activities are attributed to the incorporation of more antibacterial resin monomers in the resin composites (18wt\%) and adhesives $(10 \mathrm{wt} \%)^{39,40}$ In an investigation of the structure-property relationship of QAMs, those with a chain length of 12 or 16 were found to possess higher antibacterial potency. ${ }^{41}$ Moreover, changing the position of the functional groups in QAMs alters their anti-caries effects after their incorporation into dental resin. ${ }^{42}$ The combined use of augmented pressure adhesive displacement ( $0.3 \mathrm{MPa}$ vs. conventional $0.1 \mathrm{MPa}$ air-spray) and an experimental antibacterial adhesive containing 10 wt $\%$ MAE-DB significantly improved the caries resistance property of bonded dentin, reduced the progression of artificial carious lesions, and did not cause irreversible pulpal damage to vital teeth. ${ }^{43,44}$ Apart from in vitro models, experimental data from in vivo animal experiments also demonstrated that QAM-based dental materials exhibited potent antimicrobial efficiency and excellent biocompatibility. ${ }^{45,46}$

AMPs are a wide-ranging class of host-derived endogenous biomolecules that play important roles in innate immunity. ${ }^{47}$ Due to their broad-spectrum antimicrobial activities and low risks of developing antimicrobial resistance, they represent alternatives to traditional synthetic antimicrobial agents for developing antimicrobial materials. ${ }^{48}$ The most-widely accepted mechanism of AMPs for killing microorganisms is membrane permeabilization and disruption, as well as intracellular targeting. The latter includes inhibition of microbial functional proteins, DNA and RNA synthesis, interactions with certain intracellular targets following uptake through direct penetration and endocystosis. ${ }^{49,50}$ Apart from naturally occurring AMPs, researchers also identified AMPs from databases and developed synthetic AMPs with unique properties. ${ }^{51}$ These peptide mimics share the bactericidal mechanism of natural AMPs, but overcome their limitations, such as instability to enzymatic degradation, susceptibility to proteolysis and hydrolysis, hemolytic activity and cytotoxicity, as well as their ineffectiveness in eradicating multidrug-resistant bacteria. ${ }^{52}$ Novel technologies have been developed for manufacturing antimicrobial materials immobilized with AMPs on their surface. ${ }^{53}$ Table 3 represents some contact-killing Ti implants immobilized with AMPs. For example, calcium phosphate-AMP (Tet213, KRWWKWWRRC)-coated implants (by electrolytic deposition technique) possessed antimicrobial activity against both Gram-positive Staphylococcus aureus and Gram-negative Pseudomonas aeruginosa within $30 \mathrm{~min}$ in vitro. ${ }^{54}$ Amphipathic AMPs GL13K and DGL13K were used to directly coat dentin before the restorative procedures. The modified dentin-composites resisted in vitro hydrolytic, mechanical, thermal, acidic, and enzymatic modes of degradation. Both the AMPs and the modified dentin-composites are active against multispecies biofilms derived from caries-active individuals. $^{55}$

There are still major issues related to contact-killing antimicrobial materials. The antimicrobial activity of these materials is critically dependent on the chemical tethering procedure and the orientation of the covalently attached antimicrobial agents. Therefore, the antimicrobial activity of the resulting coating may not be as strong as those in free form. Most of these materials show antimicrobial activity via direct contact with bacteria on the immobilized antibacterial surface, without effects on planktonic 


\begin{tabular}{|llll|}
\hline Table 3. & Representative contact-killing Ti implants immobilized with AMPs & \\
\hline AMPs & Coating methods & Microorganisms or models tested & Reference \\
\hline Bacitracin & Surface tethering & Staphylococcus aureus in vitro and in a rat femur implant infection model \\
GL13K & Surface tethering & Streptococcus gordonii and Porphyromonas gingivalis in vitro & 165 \\
GZ3.27 & Surface tethering & Pseudomonas aeruginosa and Escherichia coli in vitro \\
hLF1-11 & Polymer brush & Streptococcus sanguinis and Lactobacillus salivarius in vitro & 166 \\
Melimine & Surface tethering & Pseudomonas aeruginosa in vitro, and Staphylococcus aureus in mouse and rat subcutaneous implant & 169 \\
& & infection & 167 \\
SESB2V & Surface tethering & Staphylococcus aureus and Pseudomonas aeruginosa in a rabbit keratitis model \\
Tet20 & Polymer brush & Pseudomonas aeruginosa and Staphylococcus aureus in vitro, and Staphylococcus aureus in rat \\
& subcutaneous implant infection model & 170 \\
Tet213 & Electrolytic deposition & Pseudomonas aureus and Pseudomonas aeruginosa in vitro \\
Tet213 & Polymer brush & Pseudomonas aeruginosa in vitro \\
\hline AMP antimicrobial peptide, Ti titanium & 171 \\
\hline
\end{tabular}

bacteria. ${ }^{56}$ These materials only exhibited bacteriostatic instead of bactericidal effects against the contacting bacteria. This phenomenon may be attributed to inadequacy of surface-active functional groups derived from the antimicrobial agents in killing bacterial cells on contact. Another realistic issue with contact-killing antimicrobial materials is "surface biofouling"; Dead bacterial cells or saliva-derived protein films can also be absorbed onto the surface of the antimicrobial materials, blocking functional antibacterial groups on the material surfaces, hence inactivating and reducing the antimicrobial activity of those materials. ${ }^{57}$ However, most studies of this field do not investigate the half-life for antimicrobial efficacy. It is noted that cationic polymers, QACs and metal NPs are potentially toxic to eukaryotic cells and tissues. ${ }^{58,59}$

\section{Multi-functional strategy}

Although strategies involving the release of antimicrobial agents and contact-killing have been developed, neither of these strategies has been entirely successful due to their inherent drawbacks. The biological environment within human body is complex, and antimicrobial materials with additional specific properties (e.g. remineralization or protein-repellent properties) are necessary to achieve better performance in their environments. Recently, several multifunctional antimicrobial materials have been developed to achieve augmented antimicrobial or multi-functional applications. ${ }^{60,61}$ Herein, several selected examples will be presented.

Silver has antibacterial, antifungal, and antiviral capabilities. Compared with free Ag, Ag NPs have a high surface area-to-mass ratio, and it is easier to control their releasing kinetics and to maintain long-term antibacterial effects. ${ }^{62}$ Experimental dental adhesives and composites containing AgNPs at a very low concentration are effective against plaque biofilms. ${ }^{63,64}$ To further enhance the antibacterial effects, the combined use of QAMs and AgNPs have recently been adopted for the preparation of antimicrobial dental materials. The modified materials effectively kill bacteria both on the surface of the materials and away from the surface. ${ }^{65}$ In addition, AgNPs are small enough (with a mean diameter of $40 \mathrm{~nm}$ ) to penetrate patent dentinal tubules to kill residual intratubular bacteria. ${ }^{66}$ For the application of AgNPs in dentistry, some fundamental aspects need be taken into consideration: (1) the size of AgNPs should be small enough (smaller than $50 \mathrm{~nm}$ ) to effectively penetrate the biofilm; ${ }^{67}$ (2) The incorporated amounts of AgNPs exhibit an inverse relationship with the original properties of carrier materials. Up to $0.1 \mathrm{wt} \%$
AgNPs does not significantly reduce microtensile bond strength and dentin shear bond strength of experimental adhesives, ${ }^{64}$ or the flexural strength of resin composites. ${ }^{68}$ However, $0.15 \mathrm{wt} \%$ or higher amount of AgNPs in experimental adhesives may cause a decrease in dentin bond strength. ${ }^{65}$ Moreover, as the incorporated AgNPs increased, the color of the resins become darker due to their plasmon effect, ${ }^{69}$ and $0.175 \mathrm{wt} \%$ addition gives the composite a brownish color; ${ }^{70}$ And (3) a growing concern exists regarding the toxicity of AgNPs, as well as other NPs used in dentistry to human beings. ${ }^{71}$ Similar to QACs, silver has also been successfully paired with other antimicrobial agents, such as antibiotics, metals, and NO donors. ${ }^{72-74}$

The use of NPs of amorphous calcium phosphate (NACPs) is helping in restoring the de-/re-mineralization balance, and imitates the biomineralization process of dentin and remineralizes tooth decay. ${ }^{75}$ Compared with micro-sized particles, NACPs have better ion-release profiles, and are more easily transformed into crystalline phases, such as octacalcium phosphate and apatite as a result of microcrystalline growth. ${ }^{76,77}$ Recent studies have incorporated both QAMs and NACPs into various kinds of dental materials. In in vitro studies, a NACP-QAM-modified nanocomposite inhibited biofilm and increased $\mathrm{Ca}$ and $\mathrm{PO}_{4}$ ion release at a low cariogenic $\mathrm{pH}$. At this $\mathrm{pH}$ value, $\mathrm{Ca}$ and $\mathrm{PO}_{4}$ ions would be most needed for inhibiting caries, neutralizing lactic acid produced by the bacteria and preventing caries formation. ${ }^{78} \mathrm{An}$ orthodontic adhesive containing QAMs and NACPs exhibited antibacterial and re-mineralization capabilities without adversely affecting bond strength, compared with the control. This antibacterial orthodontic adhesive represents a promising candidate in combating enamel white spot lesions and even dental caries. $^{79}$ Strong antibacterial capabilities, as well as the original mechanical properties, were maintained after a 180-day wateraging process. ${ }^{78}$ Using a rat tooth cavity model, it was found that the QAM and NACP-modified nanocomposites and adhesives facilitated healing of the dentin-pulp complex with milder pulpal inflammation and more tertiary dentin formation compared with the control groups. ${ }^{80}$

Compared with antimicrobial materials that have a permanent and single killing mechanism, multi-functional materials exhibit several advanced properties to activate bactericidal activity in response to the microenvironment of bacterial infection. ${ }^{61}$ It is impossible to directly compare the effectiveness of multifunctional strategies across different studies. Therefore, studies on comparative effectiveness with a broader range of antimicrobial agents will be necessary to select more combinations with 
synergistic and enhanced antimicrobial properties for developing novel antimicrobial dental materials.

\section{ANTIMICROBIAL PHOTODYNAMIC THERAPY (APDT)}

APDT has a history of more than 100 years, when Raab used acridine hydrochloride and visible light to inactivate Paramecia caudatum. $^{81}$ Recently, APDT has been used increasingly in dentistry for the treatment of dental caries, periodontal and endodontic diseases, due to its potential disinfecting effect on various oral microbial pathogens and biofilms. ${ }^{82}$ The working principle of APDT involves the interaction between a photosensitizer and low-energy laser light in the presence of oxygen, to generate reactive oxygen species (ROS). The bactericidal effect of APDT is attributed to oxidative damage of bacterial DNA and cell membrane system. ${ }^{83,84}$ Depending on the type of agents, photosensitizers may be delivered in various ways including intravenous injection, oral ingestion or topical application. ${ }^{85}$ It is unlikely that microorganisms would develop antimicrobial resistance to APDT due to the primitive molecular nature of ROS. Moreover, the benefits of APDT include instant suppression of causative oral bacteria, absence of systemic disturbance and undesirable effects on healthy oral cells and tissues.

Dental caries is a breakdown of teeth due to acids generated by oral microbial biofilms. ${ }^{22}$ The APDT technique may be used to prevent dental caries by facilitating the dispersion of formed biofilms and eliminating pathogens within carious lesions. ${ }^{86}$ The use of APDT offers several proposed advantages, including rapid cariogenic bacterial killing, non-invasive nature to non-carious lesions and minimum antibiotic resistance. Accumulating experimental evidences have demonstrated the susceptibility of cariogenic bacteria, either in planktonic form or as biofilms, to APDT. ${ }^{87,88}$ For instance, the photosensitizer toluidine blue Oinduced APDT has been shown to be effective against S. mutans in decayed teeth. ${ }^{89-92}$ Recently, the combined use of APDT and other treatment, such as a dental plaque-disclosing agent erythrosine ${ }^{93}$ or casein phosphopeptide-amorphous calcium phosphate achieved cariogenic bacteria killing in vitro and root surface caries arresting in vivo. ${ }^{94}$ Nevertheless, negative results have also been reported. The use of an APDT procedure with methylene blue as the photosensitizer demonstrated limited efficacy on killing of cariogenic bacteria in an in vitro multi-species biofilm model. ${ }^{95}$ Accordingly, more studies, especially randomized clinical trials (RCTs), are required to validate the antimicrobial effectiveness of APDT and to optimize its treatment parameters.

Periodontal diseases are the most common infectious diseases in humans that result in inflammatory destruction of the periodontium (i.e. gingiva, periodontal ligament, cementum, and alveolar bone). The primary etiological factor of periodontal diseases is the accumulation of microbial biofilms on tooth and root surfaces, which, in turn, induces an imbalance between the pathogenic bacteria and the host immunological potential. ${ }^{96}$ Scaling and root planning (SRP) is regarded as the gold standard treatment modality for non-surgical periodontal treatment. ${ }^{97}$ Nevertheless, SRP is associated with several limitations, including the inability to completely debride root surfaces and incomplete elimination of pathogenic bacteria in deep periodontal pockets and/or inaccessible furcation defects. ${ }^{98}$ Antimicrobial agents have also been used, but their use is not free of risks for drug resistance. ${ }^{99}$ Moreover, because of the rapid clearance of saliva, locally applied antimicrobial agents are not maintained at the therapeutic concentrations for a long enough duration. ${ }^{100}$ To surmount these limitations, certain adjunctive therapies, such as APDT have been proposed for periodontal diseases. ${ }^{83}$ Several studies have shown that periodontal pathogens are susceptible to APDT in planktonic cultures $^{91}$ plaque scrapings ${ }^{92}$ and biofilms, ${ }^{101}$ using different kinds of photosensitizers. In addition, the progression of periodontal diseases and destruction of periodontal tissues may be reduced significantly by the utilization of APDT. ${ }^{102}$ The APDT technique has been reported to be superior to the systemic antibiotic metronidazole in experimental animal models of periodontitis. $^{103}$ The technique showed comparable effects as SRP in terms of clinical parameters, ${ }^{104}$ as well as the titer of tumor necrosis factor-alpha and receptor activator of nuclear factorkappaB ligand (RANKL) in the gingival crevicular fluid of patients suffering from aggressive periodontitis. ${ }^{105} \mathrm{~A}$ meta-analysis of four RCTs indicated that a combined therapy of SRP and APDT provided additional clinical improvement in the maintenance of residual pockets during supportive periodontal therapy. ${ }^{106}$ Despite encouraging results, the longest follow-up period for the four RCTs is only 12 months. Indeed, more well-performed and long-term RCTs are still needed. In other studies using APDT as an adjunct to SRP, no beneficial effects over SRP alone were observed, which might be attributed to the inadequate exposure time for evaluating the clinical benefits. ${ }^{107}$ In addition, oral bacteria in biofilms was found to be less affected by methylene blue-induced APDT than planktonic bacteria. ${ }^{108}$ The reduced susceptibility might be due to inactivation of methylene blue, and protected phenotypes expressed by biofilm species on the agar surface. ${ }^{109}$ These controversies among different studies must be addressed with more innovative study design in future investigations.

APDT has also been employed recently for targeting microorganisms in root canal systems in vitro ${ }^{110}$ and in vivo. ${ }^{111}$ During APDT treatment in the root canal system, it is possible that the photosensitizers may pass into the periapical tissues through the root apex. This iatrogenic phenomenon may adversely affect the health status of periapical host cells after a photosensitizer is activated by light. Accordingly, it is important to determine the therapeutic window to ensure that bacteria are eliminated while host cells are left intact. To date, several in vitro studies have investigated the safety of APDT. ${ }^{112}$ The commonly used photosensitizer methylene blue ranging from $10 \mu \mathrm{mol} \cdot \mathrm{L}^{-1}$ to $100 \mu \mathrm{mol} \cdot \mathrm{L}^{-1}$ caused up to $36 \%$ and $100 \%$ killing for fibroblasts and $E$. faecalis, respectively, after exposure to red light. ${ }^{113}$ More recently, APDT has been used for root canal disinfection in a clinical setting as an adjunct to standard endodontic treatment. ${ }^{114}$

Other dental applications of APDT include treatment for periimplantitis ${ }^{115}$ and oral lichen planus, ${ }^{116}$ as well as the disinfection of acrylic denture surfaces. ${ }^{117}$ Despite promising results, several factors should be considered to obtain good therapeutic outcomes. These factors include the type of photosensitizer, adequate tissue penetration especially for deep injuries, and the combination of other treatment modalities with APDT. Recently, great attention has been paid to biodegradable polymeric materials and NPs carrying photosensitizer agents. These materials possess several advantages including: (1) increased binding between photosensitizers and bacteria to improve bactericidal efficiency, (2) reduced aggregation of photosensitizers, and (3) improved biocompatibility and biodegradability. ${ }^{118}$ The use of APDT effectively eliminated pathogenic microorganisms with few reported side effects. ${ }^{84}$ The major reported side-effect is the existence of a period of residual skin photosensitivity owing to photosensitizer accumulation, which may last for several days to weeks depending on the administered photosensitizer. Hence, patients should be instructed to avoid skin and eye exposure to bright light or sunlight until the photosensitizer is completely eliminated. ${ }^{119}$ Moreover, APDT has not been approved by the United States Food and Drug Administration for dental applications. For clinical trials, approval by the local institutional review board should be obtained prior to treatment. Universally applicable guidelines with standardized parameters should be produced in this field to direct clinical applications. 


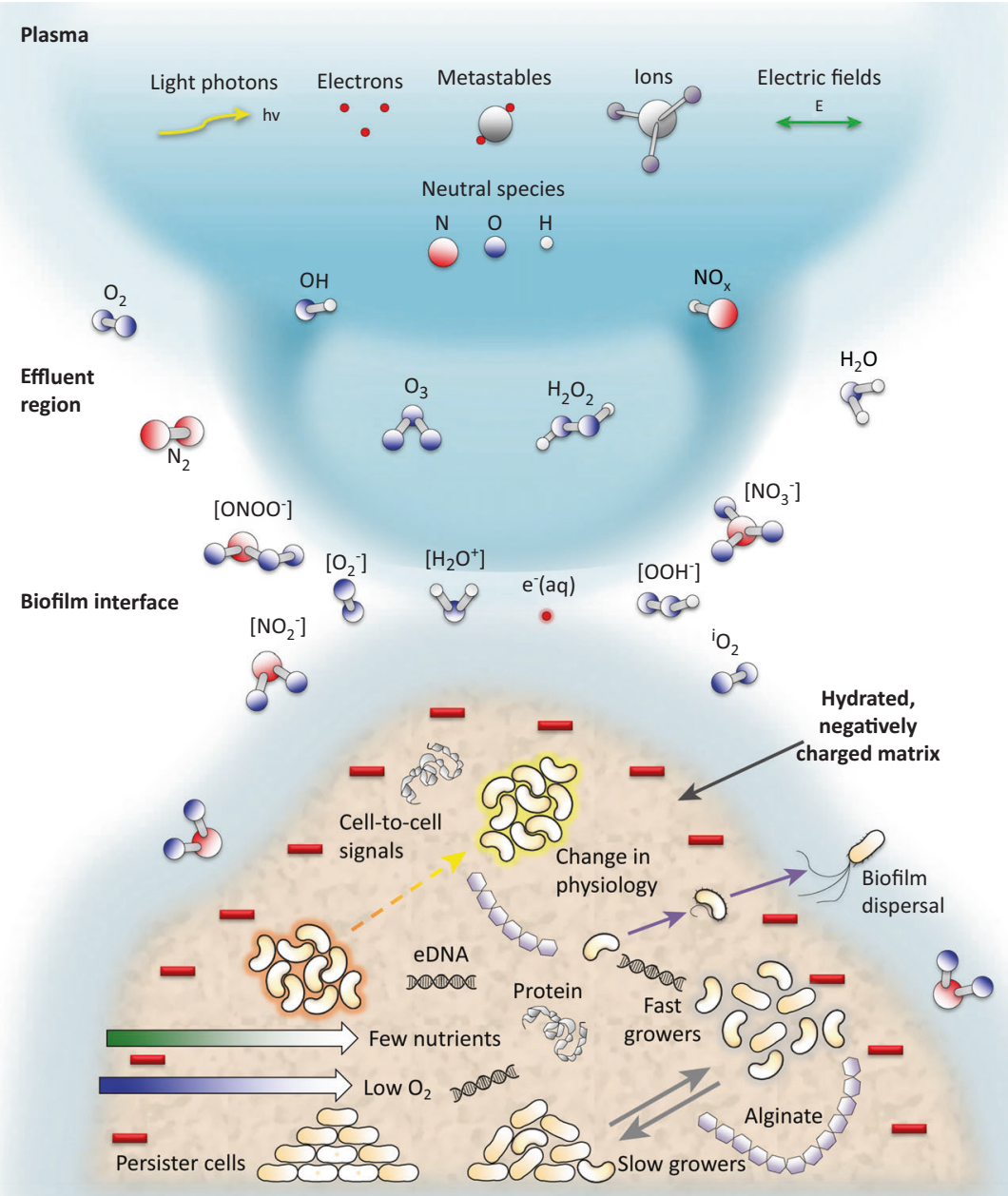

Fig. 2 Antimicrobial mechanism for cold atmospheric plasma. The plasma-derived RONS that diffuse into the biofilm and cause oxidative damages to their cell membrane, DNA, and proteinaceous enzymes, resulting in disruption of the cell membrane and cell death. eDNA extracellular DNA, RONS reactive oxygen and nitrogen species. ${ }^{120}$ Copyright 2018. Reproduced with permission from Elsevier Ltd

\section{COLD ATMOSPHERIC PLASMA (CAP)}

CAP represents a promising non-antibiotic option for the eradication and control of biofilm infections. ${ }^{120}$ The CAP technique uses a highly reactive mix of ions and electrons, radical species, molecules in the ground or excited state and quanta of electromagnetic radiation (UV photons and visible light). Compared with conventional plasma technology, CAP is operated under atmospheric conditions, and is thus feasible for in vivo applications without damaging the surrounding tissues. ${ }^{121}$ Over the last few years, accumulating experimental evidences have demonstrated the efficacy of CAP in eliminating broad-spectrum microorganisms, including Gram-negative $P$. aeruginosa and $E$. coli, Gram-positive S. aureus, B. subtilis, and M. luteus, multi-drugresistant species, such as methicillin-resistant $S$. aureus, fungi $T$. spp. and C. albicans, as well as for controlling bacterial biofilms. ${ }^{122}$ For example, CAP effectively reduce $94 \%$ of the regular bacterial skin flora ${ }^{123}$ and significantly reduced bacterial load in chronic wounds. ${ }^{124}$ Based on bacteriophage models, recent studies demonstrated that CAP is capable of reducing and inactivating human pathogenic viruses. ${ }^{125}$ Currently, the most widely accepted mechanisms of action for CAP are the occurrence of reactive oxygen and nitrogen species (RONS) as represented in Fig. $2{ }^{126}$ Most bacteria are sensitive to RONS which cause oxidative damages to their cell membrane, DNA, and proteinaceous enzymes. ${ }^{127}$ The role of charged particles, electrons, and ions in inactivation of bacteria has also been described. Charge accumulation on the bacterial membrane causes mechanical disruption of bacterial cell membrane. ${ }^{128}$ Recently, the CAP technology has been used in various dental applications including root canal treatment and dental implant surface modification. ${ }^{129}$

Microbial infection has long been recognized as the primary etiologic factor in the development of pulpitis and apical periodontitis. $^{130}$ Root canal infection is normally treated with endodontic instruments, irrigation, ultrasonics, and the application of sodium hypochlorite and other antibacterial compounds. The purpose of root canal treatment is to completely eradicate all the microorganisms within the root canal system and to prevent reinfection. ${ }^{131}$ However, these traditional treatment methods cannot completely eliminate bacteria and bacterial biofilms, with remaining cultures ranging from $40 \%$ to $60 \% .^{132}$ Development of adjunctive strategies to enhance the effectiveness of traditional antimicrobial intracanal disinfection is advantageous for successful root canal therapy. A CAP microjet device with $\operatorname{argon} / \mathrm{O}_{2}$ as the working gas was used to disinfect root canals in single-rooted extracted human teeth. ${ }^{133}$ It was found the inactivation rate of planktonic $E$. faecalis gradually increased with the treatment time and reached $98.8 \%$ after an 8-min CAP treatment. Root canals treated with CAP for 40 min showed no detectable re-infection. Indeed, E. faecalis is the most important pathogenic bacteria in non-healing apical periodontitis, as well as re-infection cases after 
root canal therapy. ${ }^{134}$ Compared with planktonic bacteria, mature intracanal biofilms are more resistant to commonly used intracanal medicaments, such as calcium hydroxide, which can damage the bacterial DNA due to its alkaline $\mathrm{pH}^{.135}$ Moreover, E. faecalis is alkali-resistant and cannot be killed by calcium hydroxide in the infected root canal. ${ }^{136}$ It has been demonstrated that CAP was effective not only for young biofilms, ${ }^{137}$ but also for mature $E$. faecalis biofilms. ${ }^{138}$ After a 10-min of CAP treatment, the regular structure of a $100-\mu \mathrm{m}$ biofilm was destroyed and replaced with ruptured bacteria. ${ }^{139}$

By using various tooth-mimicking substrates, ${ }^{140}$ cavity models, ${ }^{141}$ dentin and enamel, ${ }^{142}$ CAP treatment demonstrated effective killing of various oral cariogenic bacteria, which are responsible for secondary caries formation and disruption of the durability of resin-dentin bonds. Oral single-species biofilm of A. naeslundii, C. albicans, S. gordonii, S. mutans, S. oralis, and $S$. sanguinis could be eradicated by twice daily application of CAP for $10-30 \mathrm{~s}$ each. ${ }^{143}$ Nevertheless, several studies discussed the limitations of CAP, regarding incomplete removal of biofilms. ${ }^{144}$ Biofilm thickness is a non-negligible factor; The polymeric matrix in biofilms may reduce CAP access, preventing its penetration into its deep layer and its bactericidal effect on bacteria at the bottom of the biofilms. In addition, tolerance of microbial pathogens and biofilms to CAP is variable between species, strains of the same species, and the composition of reactive species produced by different CAP devices. Nevertheless, CAP treatment has been shown to produce no harmful effects on the mucosa and periodontal tissues, ${ }^{145,146}$ thereby alleviating concerns on the potential adverse effect on health tissues when CAP is used for oral applications. Future studies should investigate the responses of dental pulp stem cells, which are crucial for reparative dentinogenesis after CAP treatment.

Microbial colonization and subsequent biofilm formation on the dental implants are a major causative factor of implant failure and peri-implantitis. ${ }^{147}$ Treatment with CAP significantly reduced the viability and quantity of in situ biofilms on Ti discs exposed to human oral cavities for $72 \mathrm{~h}$, and its efficacy was found to be correlated with the treatment duration and plasma power. ${ }^{148}$ Importantly, no microstructural alterations of the Ti discs were observed after CAP treatment. ${ }^{149}$ The combined use of mechanical cleaning and subsequent CAP treatment improved osteoblast growth on biofilm-covered Ti discs. Cell growth on the Ti discs was comparable to the sterile control. ${ }^{150,151}$ Other investigations cautioned that complete elimination of biofilms could not be consistently achieved using CAP treatment only, and required supplementary application of other treatment modalities, such as air/water spray, air abrasion, or mechanical cleaning. ${ }^{150}$ Thus, CAP may provide adjunctive support for established decontamination techniques for treatment of peri-implantitis.

Although there is great potential for CAP to be adopted for clinical dental applications, several potential barriers to its clinical translation have been brought out. These include: (1) the effects of gas phase interactions with hydrated biological matrices, resulting in plasma-activated media; (2) a more precise definition of the plasma dose; (3) tissue-specific effects on the flux of species delivered; and (4) modulation of the host's immune responses. ${ }^{152}$

\section{SUMMARY AND PERSPECTIVE}

The past decade has witnessed the development of innovative strategies to control oral biofilm infections. Antimicrobial dental materials based on antimicrobial agent release, contact-killing, and multi-functional strategies have been developed for prevention of initial bacterial attachment and subsequent biofilm formation. Recent progress in controlled radical polymerization and click chemistry, which enables precise control over macromolecular structure, order, and functionality, has provided a powerful tool for the design and synthesis of bioactive surfaces and functional biomaterials, including antimicrobial dental materials. ${ }^{153,154}$ Novel experimental approaches for the management of microbial biofilms in clinical practice include the use of APDT as an alternative to antimicrobial regimes and mechanical removal of tenacious biofilms, and the use of CAP that shows potential advantages over conventional antimicrobial approaches. ${ }^{120,155}$

Despite the recent achievements that are summarized in the present review, it should be emphasized that many challenges remain. Most currently available data is obtained from in vitro experiments and in preclinical models in the short term. Researchers must provide quantitative evidences that these reported strategies bring real benefits under in vivo conditions and confirm their antibacterial longevity. The safety profile and development of antimicrobial resistance for these antimicrobial compounds and nanomaterials is a matter of overriding significance and needs further assessment. Appropriately designed and well-structured multi-center clinical trials are critically needed to obtain reliable comparative data to identify the most effective antibacterial solution and the most optimal parameters for utilizing these anti-biofilm strategies.

\section{ACKNOWLEDGEMENTS}

This work was supported by grant from the Open Project from State Key Laboratory of Military Stomatology (No. 2018KA02), National Key Research \& Development Program of China (2017YFC0840100 and 2017YFC0840109), National Natural Science Foundation of China (81720108011), and program for Changjiang Scholars and Innovative Research Team in University (No. IRT13051).

\section{ADDITIONAL INFORMATION}

Competing interests: The authors declare no competing interests.

\section{REFERENCES}

1. Flemming, H. C. et al. Biofilms: an emergent form of bacterial life. Nat. Rev. Microbiol. 14, 563-575 (2016).

2. Flemming, H. C. \& Wuertz, S. Bacteria and archaea on Earth and their abundance in biofilms. Nat. Rev. Microbiol. 4, 247-260 (2019).

3. Bowen, W. H., Burne, R. A., Wu, H. \& Koo, H. Oral biofilms: pathogens, matrix, and polymicrobial interactions in microenvironments. Trends Microbiol. 26, 229-242 (2018).

4. David, D. Understanding biofilm resistance to antibacterial agents. Nat. Rev. Drug Discov. 2, 114-122 (2003).

5. Morgan-Sagastume, F., Larsen, P., Nielsen, J. L. \& Nielsen, P. H. Characterization of the loosely attached fraction of activated sludge bacteria. Water Res. 42, 843-854 (2008).

6. Stoodley, P., Sauer, K., Davies, D. G. \& Costerton, J. W. Biofilms as complex differentiated communities. Annu. Rev. Microbiol. 56, 187-209 (2002).

7. Mira, A., Simon-Soro, A. \& Curtis, M. A. Role of microbial communities in the pathogenesis of periodontal diseases and caries. J. Clin. Periodontol. 44(Suppl. 18), S23-S38 (2017).

8. Lin, N. J. Biofilm over teeth and restorations: what do we need to know? Dent. Mater. 33, 667-680 (2017).

9. Allaker, R. P. The use of nanoparticles to control oral biofilm formation. J. Dent. Res. 89, 1175-1186 (2010).

10. Cloutier, M., Mantovani, D. \& Rosei, F. Antibacterial coatings: challenges, perspectives, and opportunities. Trends Biotechnol. 33, 637-652 (2015).

11. Colton, M. B. \& Ehrlich, E. Bactericidal effect obtained by addition of antibiotics to dental cements and direct filling resins. J. Am. Dent. Assoc. 47, 524-531 (1953).

12. Campoccia, D., Montanaro, L. \& Arciola, C. R. A review of the biomaterials technologies for infection-resistant surfaces. Biomaterials 34, 8533-8554 (2013).

13. Darouiche, R. O. et al. A comparison of two antimicrobial-impregnated central venous catheters. Catheter Study Group. N. Engl. J. Med. 340, 1-8 (1999).

14. Padovani, G. C. et al. Advances in dental materials through nanotechnology: facts, perspectives and toxicological aspects. Trends Biotechnol. 33, 621-636 (2015).

15. Melo, M. A., Guedes, S. F., Xu, H. H. \& Rodrigues, L. K. Nanotechnology-based restorative materials for dental caries management. Trends Biotechnol. 31, 459-467 (2013). 
16. Cheng, L. et al. Nanotechnology strategies for antibacterial and remineralizing composites and adhesives to tackle dental caries. Nanomedicine 10,627-641 (2015).

17. Liu, Y. et al. Nanotechnology-based antimicrobials and delivery systems for biofilm-infection control. Chem. Soc. Rev. 48, 428-446 (2019).

18. Nicolas, B. et al. Nitric oxide signaling in Pseudomonas aeruginosa biofilms mediates phosphodiesterase activity, decreased cyclic di-GMP levels, and enhanced dispersal. J. Bacteriol. 191, 7333-7342 (2009).

19. Taylor, P. W., Hamilton-Miller, J. M. \& Stapleton, P. D. Antimicrobial properties of green tea catechins. Food Sci. Technol. Bull. 2, 71-81 (2005).

20. Quah, S. Y., Wu, S., Lui, J. N., Sum, C. P. \& Tan, K. S. N-acetylcysteine inhibits growth and eradicates biofilm of Enterococcus faecalis. J. Endod. 38, 81-85 (2012).

21. Park, K. Controlled drug delivery systems: past forward and future back. J. Control. Release 190, 3-8 (2014).

22. Jiao, Y. et al. Quaternary ammonium-based biomedical materials: state-of-theart, toxicological aspects and antimicrobial resistance. Prog. Polym. Sci. 71, 53-90 (2017).

23. Munozbonilla, A., Muñoz-Bonilla, A. \& Fernández-García, M. Polymeric materials with antimicrobial activity. Prog. Polym. Sci. 37, 281-339 (2012).

24. Tezel, U. \& Pavlostathis, S. G. Quaternary ammonium disinfectants: microbial adaptation, degradation and ecology. Curr. Opin. Biotechnol. 33, 296-304 (2015).

25. Krasimir, V., Jessica, C. \& Griesser, H. J. Antibacterial surfaces for biomedical devices. Expert Rev. Med. Devices 6, 553-567 (2009).

26. Stephen, W. \& Hanne, I. Modes of action of three disinfectant active substances: a review. Regul. Toxicol. Pharmacol. 67, 456-467 (2013).

27. Beyth, N., Yudovin-Farber, I., Perez-Davidi, M., Domb, A. J. \& Weiss, E. I. Polyethyleneimine nanoparticles incorporated into resin composite cause cell death and trigger biofilm stress in vivo. Proc. Natl Acad. Sci. USA 107, 22038-22043 (2010).

28. Beyth, N. et al. Surface antimicrobial activity and biocompatibility of incorporated polyethylenimine nanoparticles. Biomaterials 29, 4157-4163 (2008).

29. Imazato, S., Russell, R. R. \& McCabe, J. F. Antibacterial activity of MDPB polymer incorporated in dental resin. J. Dent. 23, 1437-1443 (1994).

30. Imazato, S., Torii, M., Tsuchitani, Y., McCabe, J. F. \& Russell, R. R. Incorporation of bacterial inhibitor into resin composite. J. Dent. Res. 73, 1437-1443 (1994).

31. Imazato, S. et al. Bactericidal activity and cytotoxicity of antibacterial monomer MDPB. Biomaterials 20, 899-903 (1999).

32. Xiao, Y. H. et al. Antibacterial activity and bonding ability of an adhesive incorporating an antibacterial monomer DMAE-CB. J. Biomed. Mater. Res. Part B 90, 813-817 (2009).

33. Li, F. et al. Effects of a dental adhesive incorporating antibacterial monomer on the growth, adherence and membrane integrity of Streptococcus mutans. J. Dent. 37, 289-296 (2009).

34. Imazato, S., Ma, S., Chen, J. H. \& Xu, H. H. Therapeutic polymers for denta adhesives: loading resins with bio-active components. Dent. Mater. 30, 97-104 (2014).

35. Makvandi, P., Jamaledin, R., Jabbari, M., Nikfarjam, N. \& Borzacchiello, A. Antibacterial quaternary ammonium compounds in dental materials: a systematic review. Dent. Mater. 34, 851-867 (2018).

36. Cocco, A. R., Rosa, W. L., Silva, A. F., Lund, R. G. \& Piva, E. A systematic review about antibacterial monomers used in dental adhesive systems: current status and further prospects. Dent. Mater. 31, 1345-1362 (2015).

37. Huang, L. et al. Antibacterial effect of a resin incorporating a novel polymerizable quaternary ammonium salt MAE-DB against Streptococcus mutans. J. Biomed. Mater. Res. Part B 100, 1353-1358 (2012).

38. Huang, L. et al. Antibacterial activity and cytotoxicity of two novel cross-linking antibacterial monomers on oral pathogens. Arch. Oral Biol. 56, 367-373 (2011).

39. Cheng, L. et al. Tetracalcium phosphate composite containing quaternary ammonium dimethacrylate with antibacterial properties. J. Biomed. Mater. Res. Part B 100, 726-734 (2012).

40. Antonucci, J. M. et al. Synthesis and characterization of dimethacrylates containing quaternary ammonium functionalities for dental applications. Dent. Mater. 28, 219-228 (2012).

41. Li, F., Weir, M. D. \& Xu, H. H. Effects of quaternary ammonium chain length on antibacterial bonding agents. J. Dent. Res. 92, 932-938 (2013).

42. Liang, J. et al. The anti-caries effects of dental adhesive resin influenced by the position of functional groups in quaternary ammonium monomers. Dent. Mater. 34, 400-411 (2017).

43. Zhou, W. et al. Improved secondary caries resistance via augmented pressure displacement of antibacterial adhesive. Sci. Rep. 6, 22269 (2016).

44. Zhou, W. et al. Caries-resistant bonding layer in dentin. Sci. Rep. 6, 32740 (2016).

45. $\mathrm{Wu}, \mathrm{T}$. et al. Evaluation of novel anticaries adhesive in a secondary caries animal model. Caries Res. 52, 14-21 (2018).
46. Imazato, S., Tay, F. R., Kaneshiro, A. V., Takahashi, Y. \& Ebisu, S. An in vivo evaluation of bonding ability of comprehensive antibacterial adhesive system incorporating MDPB. Dent. Mater. 23, 170-176 (2007).

47. Silva, O. N. et al. Exploring the pharmacological potential of promiscuous hostdefense peptides: from natural screenings to biotechnological applications. Front. Microbiol. 2, 232 (2011).

48. Lima, S. M. F. et al. Antimicrobial peptide-based treatment for endodontic infections-biotechnological innovation in endodontics. Biotechnol. Adv. 33, 203-213 (2015)

49. Brogden, K. A. Antimicrobial peptides: pore formers or metabolic inhibitors in bacteria? Nat. Rev. Microbiol. 3, 238-250 (2005).

50. Di Luca, M., Maccari, G. \& Nifosì, R. Treatment of microbial biofilms in the postantibiotic era: prophylactic and therapeutic use of antimicrobial peptides and their design by bioinformatics tools. FEMS Immunol. Med. Microbiol. 70, 257-270 (2014).

51. P orto, W. F., Pires, A. S. \& Franco, O. L. Computational tools for exploring sequence databases as a resource for antimicrobial peptides. Biotechnol. Adv. 35, 337-349 (2017)

52. Fjell, C. D., Hiss, J. A., Hancock, R. E. \& Schneider, G. Designing antimicrobial peptides: form follows function. Nat. Rev. Drug Discov. 11, 37-51 (2012).

53. Onaizi, S. A. \& Leong, S. S. Tethering antimicrobial peptides: current status and potential challenges. Biotechnol. Adv. 29, 67-74 (2011).

54. Kazemzadeh-Narbat, M. et al. Antimicrobial peptides on calcium phosphatecoated titanium for the prevention of implant-associated infections. Biomaterials 31, 9519-9526 (2010).

55. Moussa, D. G., Fok, A. \& Aparicio, C. Hydrophobic and antimicrobial dentin: a peptide-based 2-tier protective system for dental resin composite restorations. Acta Biomater. 88, 251-265 (2019).

56. Tiller, J. C., Liao, C. J., Lewis, K. \& Klibanov, A. M. Designing surfaces that kill bacteria on contact. Proc. Natl Acad. Sci. USA 98, 5981-5985 (2001).

57. Li, F., Weir, M. D., Fouad, A. F. \& Xu, H. H. Effect of salivary pellicle on antibacterial activity of novel antibacterial dental adhesives using a dental plaque microcosm biofilm model. Dent. Mater. 30, 182-191 (2014).

58. Jiao, Y. et al. Methacryloxylethyl cetyl ammonium chloride induces DNA damage and apoptosis in human dental pulp cells via generation of oxidative stress. Int. J. Biol. Sci. 12, 580-593 (2016).

59. Behzadi, S. et al. Cellular uptake of nanoparticles: journey inside the cell. Chem. Soc. Rev. 46, 4218-4244 (2017).

60. Yu, Q., Wu, Z. \& Chen, H. Dual-function antibacterial surfaces for biomedical applications. Acta Biomater. 16, 1-13 (2015).

61. Wei, T., Yu, Q. \& Chen, H. Responsive and synergistic antibacterial coatings: fighting against bacteria in a smart and effective way. Adv. Healthc. Mater. 8, e1801381 (2019).

62. Damm, C., Münstedt, H. \& Rosch, A. Long-term antimicrobial polyamide $6 /$ silvernanocomposites. J. Mater. Sci. 42, 6067-6073 (2007).

63. Espinosa-Cristóbal, L. F. et al. Adherence inhibition of Streptococcus mutans on dental enamel surface using silver nanoparticles. Mater. Sci. Eng. C 33, 2197-2202 (2013).

64. Cheng, L. et al. Effects of antibacterial primers with quaternary ammonium and nano-silver on Streptococcus mutans impregnated in human dentin blocks. Dent. Mater. 29, 462-472 (2013).

65. Zhang, K. et al. Effect of quaternary ammonium and silver nanoparticlecontaining adhesives on dentin bond strength and dental plaque microcosm biofilms. Dent. Mater. 28, 842-852 (2012).

66. Cheng, L. et al. Anti-biofilm dentin primer with quaternary ammonium and silver nanoparticles. J. Dent. Res. 91, 598-604 (2012).

67. Peulen, T. O. \& Wilkinson, K. J. Diffusion of nanoparticles in a biofilm. Environ. Sci. Technol. 45, 3367-3373 (2011).

68. Cheng, L. et al. Antibacterial amorphous calcium phosphate nanocomposites with a quaternary ammonium dimethacrylate and silver nanoparticles. Dent. Mater. 28, 561-572 (2012).

69. Fan, C. et al. Development of an antimicrobial resin-a pilot study. Dent. Mater. 27, 322-328 (2011).

70. Cheng, L. et al. Effect of amorphous calcium phosphate and silver nanocomposites on dental plaque microcosm biofilms. J. Biomed. Mater. Res. B 100, 1378-1386 (2012)

71. Feng, X. et al. Application of dental nanomaterials: potential toxicity to the central nervous system. Int. J. Nanomed. 10, 3547-3565 (2015).

72. Storm, W. L. et al. Dual action antimicrobial surfaces via combined nitric oxide and silver release. J. Biomed. Mater. Res. Part A 103, 1974-1984 (2015).

73. Samani, S., Hossainalipour, S. M., Tamizifar, M. \& Rezaie, H. R. In vitro antibacterial evaluation of sol-gel-derived $\mathrm{Zn}^{-}, \mathrm{Ag}^{-}$, and $(\mathrm{Zn}+\mathrm{Ag})$-doped hydroxyapatite coatings against methicillin-resistant Staphylococcus aureus. J. Biomed. Mater Res. A 101, 222-230 (2012). 
74. Fayaz, A. M. et al. Biogenic synthesis of silver nanoparticles and their synergistic effect with antibiotics: a study against Gram-positive and Gram-negative bacteria. Nanomedicine 6, 103-109 (2010).

75. $\mathrm{Ma}$, S. et al. Adhesive materials with bioprotective/biopromoting functions. Curr. Oral Health Rep. 1, 213-221 (2014).

76. Zhao, J., Liu, Y., Sun, W. \& Yang, X. First detection, characterization, and application of amorphous calcium phosphate in dentistry. J. Dent. Sci. 7, 316-323 (2012).

77. Cheng, L. et al. Antibacterial and physical properties of calcium-phosphate and calcium-fluoride nanocomposites with chlorhexidine. Dent. Mater. 28, 573-583 (2012).

78. Cheng, L. et al. Dental plaque microcosm biofilm behavior on calcium phosphate nanocomposite with quaternary ammonium. Dent. Mater. 28, 853-862 (2012).

79. Liu, Y. et al. Antibacterial and remineralizing orthodontic adhesive containing quaternary ammonium resin monomer and amorphous calcium phosphate nanoparticles. J. Dent. 72, 53-63 (2018).

80. Li, F., Wang, P., Weir, M. D., Fouad, A. F. \& Xu, H. H. Evaluation of antibacterial and remineralizing nanocomposite and adhesive in rat tooth cavity model. Acta Biomater. 10, 2804-2813 (2014)

81. Raab, O. Ueber die Wirkung Fluorescierenden Stoffe auf Infusorien. Z. Biol. 39, 524-546 (1904).

82. Al-Shammery, D. et al. Scope of antimicrobial photodynamic therapy in orthodontics and related research: a review. Photodiagn. Photodyn. Ther. 25, 456-459 (2019)

83. Hu, X., Huang, Y. Y., Wang, Y., Wang, X. \& Hamblin, M. R. Antimicrobial photodynamic therapy to control clinically relevant biofilm infections. Front. Microbiol. 9, 1299 (2018)

84. Takasaki, A. A. et al. Application of antimicrobial photodynamic therapy in periodontal and peri-implant diseases. Periodontol. 2000 51, 109-140 (2009)

85. Konopka, K. \& Goslinski, T. Photodynamic therapy in dentistry. J. Dent. Res. 86, 694-707 (2007).

86. Wilson, M. Lethal photosensitisation of oral bacteria and its potential application in the photodynamic therapy of oral infections. Photochem. Photobiol. Sci. 3, 412-418 (2004)

87. Williams, J. A., Pearson, G. J., Colles, M. J. \& Wilson, M. The effect of variable energy input from a novel light source on the photoactivated bactericidal action of toluidine blue O on Streptococcus mutans. Caries Res. 37, 190-193 (2003).

88. Zanin, I. C., Gonçalves, R. B., Junior, A. B., Hope, C. K. \& Pratten, J. Susceptibility of Streptococcus mutans biofilms to photodynamic therapy: an in vitro study. J. Antimicrob. Chemother. 56, 324-330 (2005).

89. Burns, T., Wilson, M. \& Pearson, G. J. Effect of dentine and collagen on the lethal photosensitization of Streptococcus mutans. Caries Res. 29, 192-197 (1995).

90. Williams, J. A., Pearson, G. J., Colles, M. J. \& Wilson, M. The photo-activated antibacterial action of toluidine blue $\mathrm{O}$ in a collagen matrix and in carious dentine. Caries Res. 38, 530-536 (2004).

91. Chan, Y. \& Lai, C. H. Bactericidal effects of different laser wavelengths on periodontopathic germs in photodynamic therapy. Lasers Med. Sci. 18, 51-55 (2003).

92. Wilson, M., Sarkar, S. \& Bulman, J. S. Effect of blood on lethal photosensitization of bacteria in subgingival plaque from patients with chronic periodontitis. Lasers Med. Sci. 8, 297-303 (1993)

93. Wood, S., Metcalf, D., Devine, D. \& Robinson, C. Erythrosine is a potential photosensitizer for the photodynamic therapy of oral plaque biofilms. J. Antimicrob. Chemother. 57, 680-684 (2006).

94. Reynolds, E. C. Remineralization of enamel subsurface lesions by casein phosphopeptide-stabilized calcium phosphate solutions. J. Dent. Res. 76, 1587-1595 (1997).

95. Müller, P., Guggenheim, B. \& Schmidlin, P. R. Efficacy of gasiform ozone and photodynamic therapy on a multispecies oral biofilm in vitro. Eur. J. Oral Sci. 115, 77-80 (2007).

96. Pihlstrom, B. L., Michalowicz, B. S. \& Johnson, N. W. Periodontal diseases. Lancet 366, 1809-1820 (2005)

97. Cobb, C. M. Clinical significance of non-surgical periodontal therapy: an evidence-based perspective of scaling and root planing. J. Clin. Periodontol. 29, 6-16 (2002).

98. Sherman, P. R. et al. The effectiveness of subgingival scaling and root planning. I. Clinical detection of residual calculus. J. Periodontol. 61, 3-8 (1990).

99. Roca, I. et al. The global threat of antimicrobial resistance: science for intervention. New Microbes New Infect. 6, 22-29 (2015)

100. Horev, B. et al. PH-Activated nanoparticles for controlled topical delivery of farnesol to disrupt oral biofilm virulence. ACS Nano 9, 2390-2404 (2015).

101. Dobson, J. \& Wilson, M. Sensitization of oral bacteria in biofilms to killing by light from a low-power laser. Arch. Oral Biol. 37, 883-887 (1992).
102. Kömerik, N. et al. In vivo killing of Porphyromonas gingivalis by toluidine bluemediated photosensitization in an animal model. Antimicrob. Agents Chemother. 47, 932-940 (2003)

103. Zhang, J. et al. Photodynamic therapy versus systemic antibiotic for the treatment of periodontitis in a rat model. J. Periodontol. 90, 798-807 (2019).

104. de Oliveira, R. R., Schwartz-Filho, H. O., Novaes, A. B. Jr \& Taba, M. Jr. Antimicrobial photodynamic therapy in the non-surgical treatment of aggressive periodontitis: a preliminary randomized controlled clinical study. J. Periodontol. 78, 965-973 (2007)

105. de Oliveira, R. R. et al. Antimicrobial photodynamic therapy in the non-surgical treatment of aggressive periodontitis: cytokine profile in gingival crevicular fluid, preliminary results. J. Periodontol. 80, 98-105 (2009).

106. Xue, D. \& Zhao, Y. Clinical effectiveness of adjunctive antimicrobial photodynamic therapy for residual pockets during supportive periodontal therapy: a systematic review and meta-analysis. Photodiagn. Photodyn. Ther. 17, 127-133 (2017).

107. Yilmaz, S. et al. Effect of galium arsenide diode laser on human periodontal disease: a microbiological and clinical study. Lasers Surg. Med. 30, 60-66 (2002).

108. Fontana, C. R. et al. The antibacterial effect of photodynamic therapy in dental plaque-derived biofilms. J. Periodontal Res. 44, 751-759 (2009).

109. Whiteley, M. et al. Gene expression in Pseudomonas aeruginosa biofilms. Nature 413, 860-864 (2001)

110. Fimple, J. L. et al. Photodynamic treatment of endodontic polymicrobial infection in vitro. J. Endod. 34, 728-734 (2008).

111. Garcez, A. S., Nuñez, S. C., Hamblin, M. R. \& Ribeiro, M. S. Antimicrobial effects of photodynamic therapy on patients with necrotic pulps and periapical lesion. J. Endod. 34, 138-142 (2008)

112. $\mathrm{Xu}, \mathrm{Y}$. et al. Endodontic antimicrobial photodynamic therapy: safety assessment in mammalian cell cultures. J. Endod. 35, 1567-1572 (2009).

113. George, S. \& Kishen, A. Photophysical, photochemical, and photobiological characterization of methylene blue formulations for light-activated root canal disinfection. J. Biomed. Opt. 12, 034029 (2007).

114. Bonsor, S. J., Nichol, R., Reid, T. M. \& Pearson, G. J. An alternative regimen for root canal disinfection. Br. Dent. J. 201, 101-105 (2006).

115. Mizutani, K. et al. Lasers in minimally invasive periodontal and peri-implant therapy. Periodontol. 2000 71, 185-212 (2016).

116. Bliss, J. M., Bigelow, C. E., Foster, T. H. \& Haidaris, C. G. Susceptibility of Candida species to photodynamic effects of photofrin. Antimicrob. Agents Chemother. 48, 2000-2006 (2004).

117. Varela Kellesarian, S. et al. Efficacy of antimicrobial photodynamic therapy in the disinfection of acrylic denture surfaces: a systematic review. Photodiagn. Photodyn. Ther. 17, 103-110 (2017).

118. Zhang, K. et al. Developing a new generation of therapeutic dental polymers to inhibit oral biofilms and protect teeth. Materials 11, pii: E1747 (2018).

119. Feng, L. et al. NIR-driven graphitic-phase carbon nitride nanosheets for efficient bioimaging and photodynamic therapy. J. Mater. Chem. B 4, 8000-8008 (2016).

120. Gilmore, B. F. et al. Cold plasmas for biofilm control: opportunities and challenges. Trends Biotechnol. 36, 627-638 (2018).

121. Isbary, G. et al. Cold atmospheric plasma devices for medical issues. Expert Rev. Med. Devices 10, 367-377 (2013).

122. Bourke, P., Ziuzina, D., Han, L., Cullen, P. J. \& Gilmore, B. F. Microbiological interactions with cold plasma. J. Appl. Microbiol. 123, 308-324 (2017).

123. Lademann, O. et al. Skin disinfection by plasma-tissue interaction: comparison of the effectivity of tissue-tolerable plasma and a standard antiseptic. Skin Pharmacol. Physiol. 24, 284-288 (2011).

124. Isbary, G. et al. Successful and safe use of 2 min cold atmospheric argon plasma in chronic wounds: results of a randomized controlled trial. Br. J. Dermatol. 167, 404-410 (2012).

125. Weiss, M. A. et al. Virucide properties of cold atmospheric plasma for future clinical applications. J. Med. Virol. 89, 952-959 (2017).

126. Graves, D. B. The emerging role of reactive oxygen and nitrogen species in redox biology and some implications for plasma applications to medicine and biology. J. Phys. D. Appl. Phys. 45, 263001 (2012).

127. Gallagher, M. J. et al. Rapid inactivation of airborne bacteria using atmospheric pressure dielectric barrier grating discharge. IEEE Trans. Plasma Sci. 35, 1501-1510 (2007).

128. Mendis, D. A., Rosenberg, M. \& Azam, F. A note on the possible electrostatic disruption of bacteria. IEEE Trans. Plasma Sci. 28, 1304-1306 (2000).

129. Liu, Y., Liu, Q., Yu, Q. S. \& Wang, Y. Nonthermal atmospheric plasmas in dental restoration. J. Dent. Res. 95, 496-505 (2016).

130. Chavez de Paz, L. E. Redefining the persistent infection in root canals: possible role of biofilm communities. J. Endod. 33, 652-662 (2007).

131. Matsuo, T. et al. An immunohistological study of the localization of bacteria invading root pulpal walls of teeth with periapical lesions. J. Endod. 29, 194-200 (2003). 
132. Siqueira, J. F. et al. Efficacy of instrumentation techniques and irrigation regimens in reducing the bacterial population within root canals. J. Endod. 28, 181-184 (2002).

133. Wang, R. et al. The effect of an atmospheric pressure, dc nonthermal plasma microjet on tooth root canal, dentinal tubules infection and reinfection prevention. Plasma Med. 1, 143-155 (2011).

134. Dahlén, G., Samuelsson, W., Molander, A. \& Reit, C. Identification and antimicrobial susceptibility of enterococci isolated from the root canal. Oral Microbiol. Immunol. 15, 309-312 (2000).

135. Sathorn, C., Parashos, P. \& Messer, H. Antibacterial efficacy of calcium hydroxide intracanal dressing: a systematic review and meta-analysis. Int. Endod. J. 40, 2-10 (2007).

136. Nakajo, K., Nakazawa, F., Iwaku, M. \& Hoshino, E. Alkali-resistant bacteria in root canal systems. Oral Microbiol. Immunol. 19, 390-394 (2004).

137. Jiang, C., Schaudinn, C., Jaramillo, D. E., Webster, P. \& Costerton, J. W. In vitro antimicrobial effect of a cold plasma jet against Enterococcus faecalis biofilms. ISRN Dent. 2012, 295736 (2012).

138. Li, Y. et al. Evaluation of cold plasma treatment and safety in disinfecting 3-week root canal Enterococcus faecalis biofilm in vitro. J. Endod. 41, 1325-1330 (2015).

139. Pan, J. et al. Cold plasma therapy of a tooth root canal infected with Enterococcus faecalis biofilms in vitro. J. Endod. 39, 105-110 (2013).

140. Blumhagen, A. et al. Plasma deactivation of oral bacteria seeded on hydroxyapatite disks as tooth enamel analogue. Am. J. Dent. 27, 84-90 (2014)

141. Sladek, R. E. J., Stoffels, E., Walraven, R., Tielbeek, P. J. A. \& Koolhoven, R. A Plasma treatment of dental cavities: a feasibility study. IEEE Trans. Plasma Sci. 32, 1540-1543 (2004).

142. Rupf, S. et al. Killing of adherent oral microbes by a non-thermal atmospheric plasma jet. J. Med. Microbiol. 59, 206-212 (2010).

143. Duarte, S. et al. Air plasma effect on dental disinfection. Phys. Plasmas 18, 073503 (2011)

144. Sladek, R. E., Filoche, S. K., Sissons, C. H. \& Stoffels, E. Treatment of Streptococcus mutans biofilms with a nonthermal atmospheric plasma. Lett. Appl. Microbiol. $\mathbf{4 5}$ 318-323 (2007).

145. Liu, D. et al. Bacterial-killing effect of atmospheric pressure non-equilibrium plasma jet and oral mucosa response. J. Huazhong Univ. Sci. Technol. Med. Sci. 31, 852-856 (2011).

146. Molnar, I., Papp, J., Simon, A. \& Anghel, S. D. Deactivation of Streptococcus mutans biofilms on a tooth surface using $\mathrm{He}$ dielectric barrier discharge at atmospheric pressure. Plasma Sci. Technol. 15, 535-541 (2013).

147. Campoccia, D., Montanaro, L. \& Arciola, C. R. A review of the clinical implications of anti-infective biomaterials andinfection-resistant surfaces. Biomaterials $\mathbf{3 4}$ 8018-8029 (2013)

148. Idlibi, A. N. et al. Destruction of oral biofilms formed in situ on machined titanium (Ti) surfaces by cold atmospheric plasma. Biofouling 29, 369-379 (2013).

149. Rupf, S. et al. Removing biofilms from microstructured titanium ex vivo: a novel approach using atmospheric plasma technology. PLOS ONE 6, e25893 (2011)

150. Duske, K. et al. Cold atmospheric plasma in combination with mechanical treatment improves osteoblast growth on biofilm covered titanium discs. Biomaterials 52, 327-334 (2015).

151. Matthes, R. et al. Osteoblast growth, after cleaning of biofilm-covered titanium discs with air-polishing and cold plasma. J. Clin. Periodontol. 44, 672-680 (2017).

152. Pei, Y. et al. Biological activities and potential oral applications of $n$-acetylcysteine: progress and prospects. Oxid. Med. Cell. Longev. 2018, 2835787 (2018).

153. Xu, F. J., Neoh, K. G. \& Kang, E. T. Bioactive surfaces and biomaterials via atom transfer radical polymerization. Prog. Polym. Sci. 34, 719-761 (2009).

154. Wen, T. \& Becker, M. L. "Click" reactions: a versatile toolbox for the synthesis of peptide-conjugates. Chem. Soc. Rev. 43, 7013-7039 (2014).

155. Soukos, N. S. \& Goodson, J. M. Photodynamic therapy in the control of oral biofilms. Periodontol. 2000 55, 143-166 (2011).

156. Kuang, X., Chen, V. \& Xu, X. Novel approaches to the control of oral microbial biofilms. Biomed. Res. Int. 2018, 6498932 (2018).
157. Jain, A. et al. Antimicrobial. Polym. Adv. Healthc. Mater. 3, 1969-1985 (2014).

158. Paladini, F., Pollini, M., Sannino, A. \& Ambrosio, L. Metal-based antibacterial substrates for biomedical applications. Biomacromolecules 16, 1873-1885 (2015).

159. Seabra, A. B., Justo, G. Z. \& Haddad, P. S. State of the art, challenges and perspectives in the design of nitric oxide-releasing polymeric nanomaterials for biomedical applications. Biotechnol. Adv. 33, 1370-1379 (2015).

160. Michl, T. D. et al. Nitric oxide releasing plasma polymer coating with bacteriostatic properties and no cytotoxic side effects. Chem. Commun. 51, 7058-7060 (2015).

161. Weber, D. J. \& Rutala, W. A. Self-disinfecting surfaces: review of current methodologies and future prospects. Am. J. Infect. Control. 41, S31-S35 (2013).

162. Yueh, M. F. \& Tukey, R. H. Triclosan: a widespread environmental toxicant with many biological effects. Annu. Rev. Pharmacol. Toxicol. 56, 251-272 (2016).

163. Koo, $\mathrm{H}$. et al. Inhibition of Streptococcus mutans biofilm accumulation and polysaccharide production by apigenin and tt-farnesol. J. Antimicrob. Chemother. 52, 782-789 (2003).

164. Feghali, K., Feldman, M., La, V. D., Santos, J. \& Grenier, D. Cranberry proanthocyanidins: natural weapons against periodontal diseases. J. Agric. Food Chem. 60, 5728-5735 (2012)

165. Nie, B., Ao, H., Zhou, J., Tang, T. \& Yue, B. Biofunctionalization of titanium with bacitracin immobilization shows potential for anti-bacteria, osteogenesis and reduction of macrophage inflammation. Colloids Surf. B 145, 728-739 (2016).

166. Chen, X., Hirt, H., Li, Y., Gorr, S. U. \& Aparicio, C. Antimicrobial GL13K peptide coatings killed and ruptured the wall of Streptococcus gordonii and prevented formation and growth of biofilms. PLOS ONE 9, e111579 (2014).

167. Dezoysa, G. H. \& Sarojini, V. A feasibility study exploring the potential of novel battacin lipopeptides as antimicrobial coatings. ACS Appl. Mater. Interfaces $\mathbf{9}$ 1373-1383 (2016).

168. Godoy-Gallardo, M. et al. Antibacterial properties of hLf1-11 peptide onto titanium surfaces: a comparison study between silanization and surface initiated polymerization. Biomacromolecules 16, 483-496 (2015).

169. Chen, R., Willcox, M. D., Ho, K. K., Smyth, D. \& Kumar, N. Antimicrobial peptide melimine coating for titanium and its in vivo antibacterial activity in rodent subcutaneous infection models. Biomaterials 85, 142-151 (2016).

170. Tan, X. W. et al. Effectiveness of antimicrobial peptide immobilization for preventing perioperative cornea implant-associated bacterial infection. Antimicrob. Agents Chemother. 58, 5229-5238 (2014).

171. Gao, G. et al. The biocompatibility and biofilm resistance of implant coatings based on hydrophilic polymer brushes conjugated with antimicrobial peptides. Biomaterials 32, 3899-3909 (2011).

172. Gao, G. et al. Antibacterial surfaces based on polymer brushes: investigation on the influence of brush properties on antimicrobial peptide immobilization and antimicrobial activity. Biomacromolecules 12, 3715-3727 (2011).

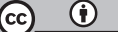

Open Access This article is licensed under a Creative Commons Attribution 4.0 International License, which permits use, sharing, adaptation, distribution and reproduction in any medium or format, as long as you give appropriate credit to the original author(s) and the source, provide a link to the Creative Commons license, and indicate if changes were made. The images or other third party material in this article are included in the article's Creative Commons license, unless indicated otherwise in a credit line to the material. If material is not included in the article's Creative Commons license and your intended use is not permitted by statutory regulation or exceeds the permitted use, you will need to obtain permission directly from the copyright holder. To view a copy of this license, visit http://creativecommons. org/licenses/by/4.0/.

(C) The Author(s) 2019 